\section{TP Periodica Polytechnica \\ Chemical Engineering}

58(Sup), pp. 11-16, 2014

DOI: $\underline{10.3311 / P P C h .7284}$

http://www.pp.bme.hu/ch/article/view/7284

Creative Commons Attribution (i)

RESEARCH ARTICLE

\title{
Single Haemoglobin Nanocapsules as Test Materials for Artificial Blood
}

Imre Hegedüs / Éva Kiss-Tóth Dojcsak / Adrienn Juhászné Szalai / Zita Lovrity János Emmer / Péter Koska / Bertalan Fodor / Endre Nagy

ReCeived 15 November 2012; Accepted 26 April 2013

\section{Abstract}

Single protein nanocapsules (SPNs) means that each individual protein molecules are coated with a very thin polymer layer. The polymer chains which are porous enough to allow enzymatic functions are bound covalently to the protein molecule. According to our previous results the polymer layer can essentially stabilize different types of enzymes, e.g. its stability became to 50-70 times longer than that of the native ones. The heat stability (at $80{ }^{\circ} \mathrm{C}$ SPNs has activity after 24 hours) and the $\mathrm{pH}$-stability (from $\mathrm{pH}=1.5$ to $\mathrm{pH}=12.0$ ) of the covered enzyme can essentially be improved comparing to the native enzymes. Our results show, that SPNs have a good features as drug carriers: acrylamide-bisacrylamide copolymer layer can carries bovine serum albumin molecules across the blood brain barrier in rat brain. We synthesized single haemoglobin nanocapsules with acrylamide-bisacrylamide copolymer on the surface of the molecules (PAAHgB) and their size, homogeneity, aggregation status, zeta potential were investigated compared with other nanomaterials.

\section{Keywords}

single haemoglobin nanocapsules $\cdot$ artificial blood $\cdot$ biocompatibility - allergic reaction

\section{Imre Hegedüs}

Research Institute of Chemical and Process Engineering,

Univesity of Pannonia, Egyetem str. 10., H-8200 Veszprém, Hungary

e-mail: hegedus@mukki.richem.hu

\section{Endre Nagy}

Research Institute of Chemical and Process Engineering,

Univesity of Pannonia, Egyetem str. 10., H-8200 Veszprém, Hungary

Éva Kiss-Tóth Dojcsak, Adrienn Juhászné Szalai, Zita Lovrity,

János Emmer, Péter Koska, Bertalan Fodor

Department of Nanobiotechnology and Regenerative Medicine,

University of Miskolc, Faculty of Health Care, Miskolc, Hungary

\section{Introduction}

Proteins usually catalyze biological reactions and have enzymatic function. Enzymes are bioreactors with high specificity and selectivity. But enzymes have a great sensitivity and a relatively brief life-time [1]. The relatively short lifetime of enzymes and their sensibility to change in the environment ( $\mathrm{pH}$, temperature, mechanical stress, etc.) tends to limit their biotechnological application. The increase of the lifetime and stability of enzymes are crucial to widen usage of enzymes. Improvement in enzyme stability can reduce the amount of enzyme required, can extend the lifetime of enzymes and can increase the reuse of enzymes [2-7]. Enzyme immobilization to the surface or onto the inner cavities of greater structures with adsorption or covalent linkage is an effective strategy to increase its lifetime $[2,3]$. Covalent linkage between the enzyme molecule and carrier material can reduce the unfolding mechanism of ternary structure of enzyme molecule and increase the stability of enzyme [4]. During the last decade there is a growing interest in minimized-size enzyme carriers $[8,9]$.

Single enzyme nanocapsules (SEN), or single protein nanocapsules (SPN) mean that a single protein molecule is covered with a few nanometer thick polymer layer [10-15] (Figure 1: Structure). This spatial polymer layer is thin and porous and allows the diffusion of substrate molecules to the active centre of the enzyme. Single enzyme nanoparticles involve the advantages of the multi-point covalent attachment [4] and closing of molecules onto inner cavities [16]. This technique needs a special polymerization step: in situ polymerization starting from the previously modified surface of the protein molecules ("Grafting from" method [9]) (Figure 1: Structure).

The quaternary protein structures (e.g. tetrameric haemoglobin molecules), as a functional unit does not change during the preparation of the single protein nanocapsules, i.e. covering enzymes by a thin polymeric layer (Figure 1: Structure). It has been proved that single enzyme nanocapsules, using organic/inorganic hybrid layer [10,12,13,14] organic acrylic copolymer [11,15], hyperhranched polymer layer [18] or superparamagnetic layer $[19,20]$, can essentially stabilize enzymes. 


\section{Structure}

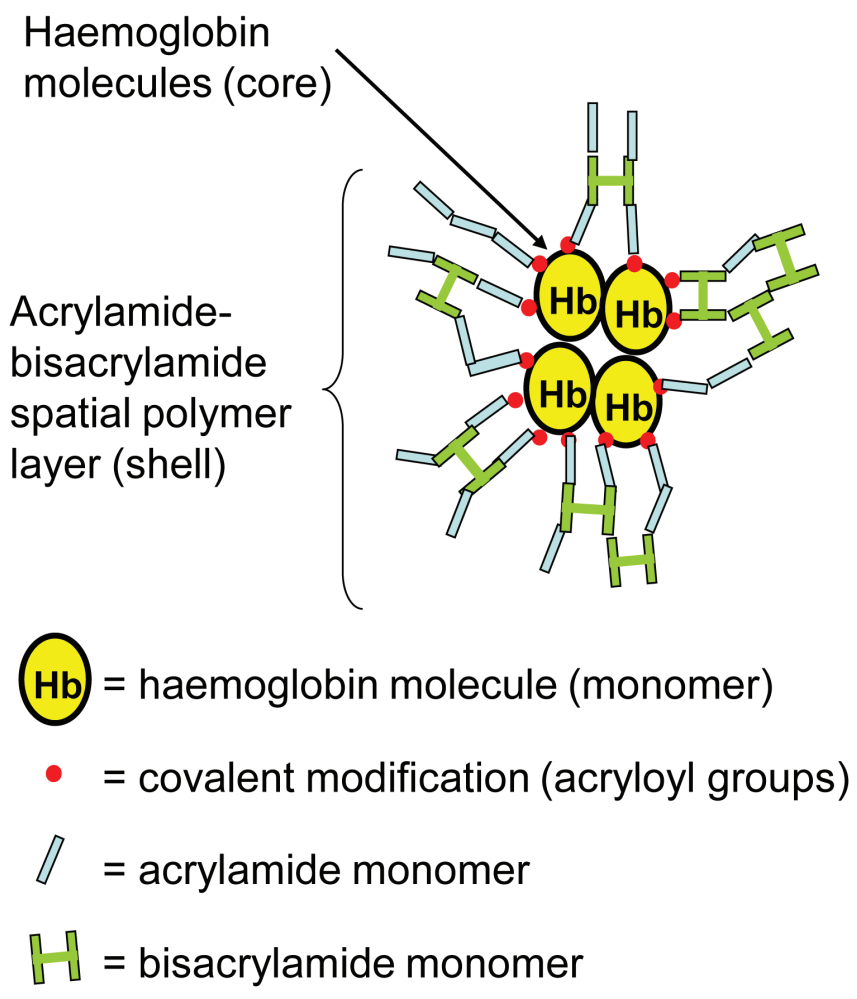

\section{Functions}

\section{Physico-chemical stabilization}
a) Mechanical stability
b) Heat stability
c) $\mathrm{pH}$-stability
d) Quaternary structures

\section{Biological stablization against proteases}

\section{Nanocarrier}
a) Blood brain barrier
b) Intracellular carrier

Fig. 1. Structure and functions of acrylamide-bisacrylamide nano-layer on single protein nanocapsules

The nano-capsule around the enzymes is multifunctional (Figure 1: Functions). Single protein nanocapsules have 1) stabilization function a) mechanical stability, when under mechanical stress (circular stirring) the single enzyme nanocapsules are more stable than natural enzymes (enzymes without nano-layer) $[12,13,14]$; b) heat stability: when at extremely high temperature $\left(80^{\circ} \mathrm{C}\right)$ single enzyme nanocapsules have greater stability than natural enzymes [12,13,14]. c) $\mathrm{pH}$-stability: at extremely acidic $(\mathrm{pH}=1.5)$ or alkaline $(\mathrm{pH}=12.0) \mathrm{pH}$-values the activity of single enzyme nanocapsules are not reduced essentially, while the natural enzymes almost loose their activities [12,14]. d) The polymer nanolayer around the enzymes can retain the quaternary structure of enzymes e.g. $\beta$-xylosidase enzymes from Thermobifida fusca species (not published results). 2) Single protein nanocapsules increase the biological stability of enzymes against protease enzymes in the systemic circulation [21]. 3) Single protein nanocapsules have a drug carrier function a) they can carry the encapsulated proteins as drugs through the blood-brain barrier [15]; b) they also can deliver protein drugs at intracellular level [21,22]. Polymers are usually used as protein drug carriers [23], but these micrometer-size carriers cannot stabilize proteins [24].
The immunogenity and nanotoxicity of SPNs has not been studied previously though it is essential for any biomedical applications. Haemoglobin molecules have enzyme-like function and its structural stability is essential for a good function. For this reason human haemoglobin molecules $(\mathrm{HgB})$ were encapsulated and single haemoglobin nanocapsules (PAAHgB) were synthesized. Synthesis of artificial blood is one of the most invested research area worldwide. Encapsulation of haemoglobin is the most common technique used for artificial blood delivery [25]. Stability of PAAHgBs was investigated by the measurement of the size distribution and melting point analysis. Nano-sized therapeutics usually inducts an extremely complex immune response (complement activation, activation of granulocyte cells, vasoactive mediator actions, etc.) [26]. Basophilic granulocyte test measure the activation of allergic reaction by the samples. Investigation of biocompatibility of PAAHgBs can be started by the measurement of basophilic granulocyte activation.

\section{Experimental section}

\subsection{Materials}

Chemicals: Acryloyl chloryde, (Sigma), disodium hydrogenphosphate, potassium dihydrogenphosphate (Spektrum-3d, 
Scharlau), acrylamide, bisacrylamide (Sigma), tetramethyl ethylenediamin (Sigma), 3,5-dinitrosalicylic acid (Sigma), sodium metabisulphid (Spektrum-3D), phenol (Sigma), sodium peroxodisulphate (Sigma), N,N,N',N'tetramethylethylenediamine (TEMED, Sigma-Aldrich), BasoTest (Glycotope Biotechnology, Heidelberg, Germany), different types of liposomes (Seroscience Ltd), multiwall carbon nanotubes (MWCNT, University of Szeged). Instruments: Nanosizer ZS (Malvern), FACS Calibur (Becton Dickinson)

\subsection{Methods}

Preparation of single haemoglobin nanocapsules (PAAHgB): $335 \mathrm{mg}$ of human haemoglobin was solved in $25 \mathrm{ml}$ of phosphate buffer $(120 \mathrm{mM}, \mathrm{pH}=7.15$, with a three times ion exchanged water, specific conductivity: $\rho=8.15 \mu \mathrm{S}$ ). Modification of haemoglobin on the surface: the solution was cooled to $0^{\circ} \mathrm{C}$ and $112 \mu \mathrm{l}$ acryloyl chloride was added and was stirred over a half an hour. $152 \mu \mathrm{l}$ of acrylamide/bisacylamide (10: 1 molar ratio of acrylamide: bisacrylamide) and $2.53 \mathrm{mg}$ ammoniumperoxodisulphate and $1.5 \mu \mathrm{l}$ TEMED initiator was added into the solution under $\mathrm{N}_{2}$-atmosphere to initiate the polymerization reaction over 6 hours. For the separation of the reagents and byproducts dialysis was used (with a $12 \mathrm{~mm}$ diameter, $10 \mathrm{kDa}$ cutoff dialysis tube, for $2 \times 6$ hours at $2^{\circ} \mathrm{C}$ with a $120 \mathrm{mM}, \mathrm{pH}=7.15$ phosphate buffer).

For direct basophil activation we studied the following nanomaterials: different kinds of functionalized multiwall carbon nanotubes (MWCNT: CNT-OH, CNT-COOH), nanofiber, micro- and nanosoot particles, polyacrylamide gel (PAA), polyacrylamide gel encapsulated haemoglobin (PAAHgB) and liposomes with various lipid composition. We determined the particle size, size distribution and zeta potential with Malvern NanoZS DLS instrument. The nanomaterials were incubated for $15 \mathrm{~min}$ with peripheral blood specimens and the degree of activated basophils (co-expression of IgE and CD63 markers on the cell surface) were examined by FACS analysis.

\section{Results and discussion}

\subsection{Size distribution of single haemoglobin nanocapsules}

The size distribution and melting point detection were measured by dynamic light scattering (DLS) method, Zetasizer Software Nano series, Zetasizer v6.20. The concentration of samples was $3.36 \mathrm{mg} / \mathrm{ml}$. The melting point of natural $\mathrm{HgB}$ molecules (Figure 2A) and single haemoglobin nanocapsules was measured to analyse the stability of nanocapsules (Figure 2B). The melting point is the same in both cases and it means that the heat stability of single haemoglobin nanocapsules is not worse than the native haemoglobin molecules.

Size distribution was measured in the function of the concentration of single haemoglobin nanocapsules (PAAHgB) and in the function of temperature (Figure 3). Polyacrylamidebisacry-
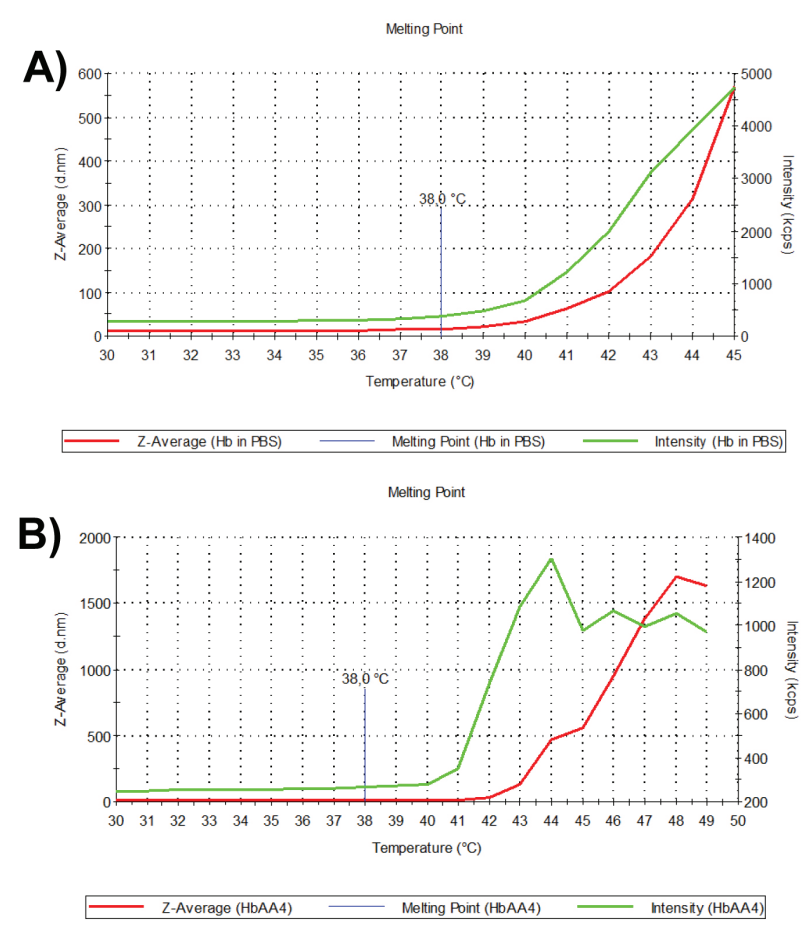

Fig. 2. Melting point analysis A) natural haemoglobin as a control B) $\mathrm{PAAHgB}$

lamide gel (PAA) in a same molar ratio and weight was used as control material.

Results show that the size distribution of PAA is between $100 \mathrm{~nm}$ and $1000 \mathrm{~nm}$ at $25^{\circ} \mathrm{C}$ (Figure 3). The mean size of PAAHgB sample is less than $10 \mathrm{~nm}$ at $25^{\circ} \mathrm{C}$ and $30^{\circ} \mathrm{C}$. This size range is suitable for biomedical applications. Size distribution is homogeneous at these temperatures. The size distribution has two peaks at $45^{\circ} \mathrm{C}$. One of these peaks falls in size range of less than $10 \mathrm{~nm}$ and the other one, in range of higher than $1000 \mathrm{~nm}$. At $48^{\circ} \mathrm{C}$ there is only one peak in the size distribution of PAAHgB and its mean value is larger than $1000 \mathrm{~nm}$. These results show that the aggregation of $\mathrm{PAAHgB}$ is occurring at about $40^{\circ} \mathrm{C}$ and the whole amount of $\mathrm{PAAHgB}$ is aggregated at $48^{\circ} \mathrm{C}$.

\subsection{Comparison of different nanomaterials containing haemoglobin molecules}

\subsubsection{Zeta potential}

We compared the size and zeta potential of different types of native nanomaterials with single haemoglobin nanocapsules (Figure 4).

In a stock solution of the empty (PAA) and $\mathrm{HgB}$ loaded polyacrylamide gel particles (PAAHgB) $(13.44 \mathrm{mg} / \mathrm{ml} \mathrm{HgB}$ in both cases) had the highest size. The lower size was observed in the case of liposome samples. The distribution range was quite wide (except liposomes). The monodispersity of particles was the best also of these materials. The range of zeta potential was between -3.56 and -47.2 . 
Size Distribution by Intensity

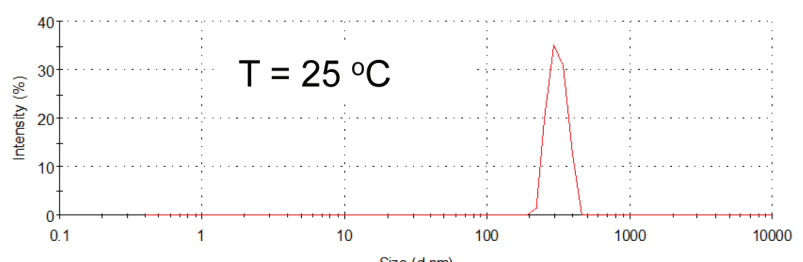

AA

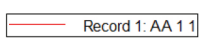

Size Distribution by Intensity

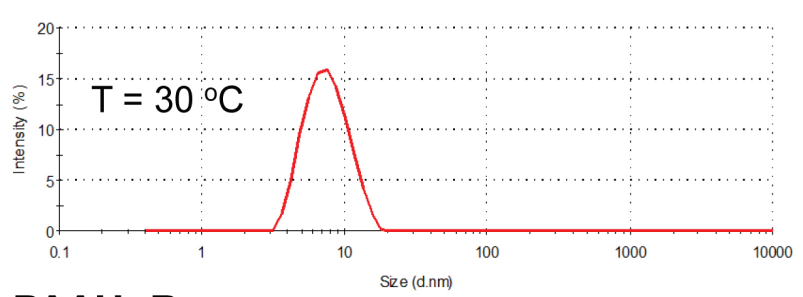

PAAHgB

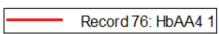

Size Distribution by Intensit/

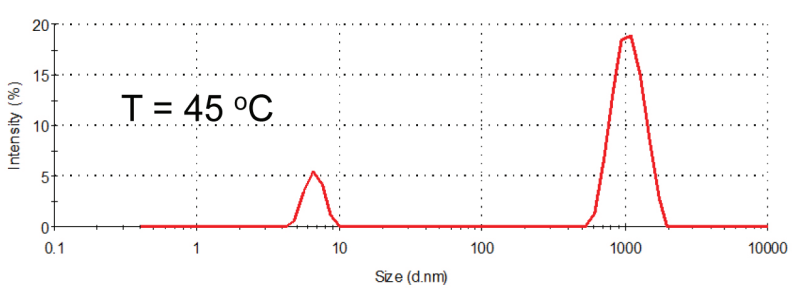

PAAHgB

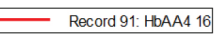

Fig. 3. Size distribution of PAA and PAAHgB in different temperatures

Zeta potential values larger than $-35 \mathrm{mV}$ yield better stability of nanoparticle, while that generally results in short-term stability of the suspension in range between $-10 \mathrm{mV}$ and $-30 \mathrm{mV}$. PAAHgB samples have low negative zeta potential and they aggregate in concentrated stock solution $(13.44 \mathrm{mg} / \mathrm{ml})$, but liposomes (LipA and LipB) have high zeta potential values.

\subsection{Basophile activation test}

The size, homogeneity and aggregation status are important physico-chemical parameters that determine the biological behaviour of nanomaterials, and ultimately toxicity. In addition, the chemical composition is also important. In our work we demonstrated that the nanomaterials play an important role in the activation process of basophils - as a part of allergic reactions. This effect depends on the above-mentioned parameters. According to our study the basophil activation capacity of PAAHgB nanoparticles is slightly elevated comparing to the background results, but it is significantly smaller than the positive control (fMLP) (Figure 5). The samples treated with wash solution instead of allergen were the negative control. The activation level of these samples gives the background activation of the system. In case of the same chemical composition

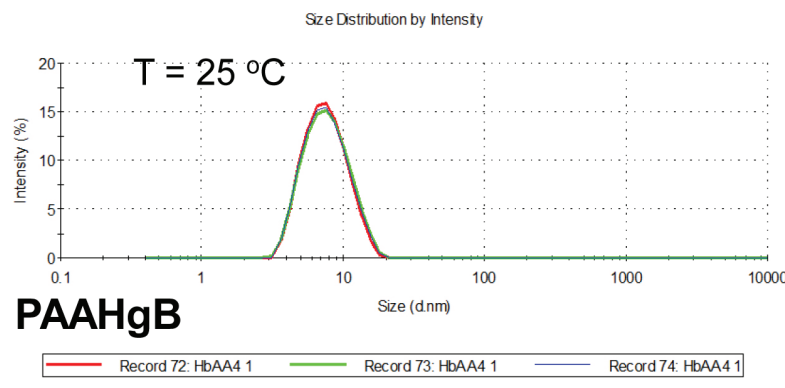

Size Distribution by Intensity

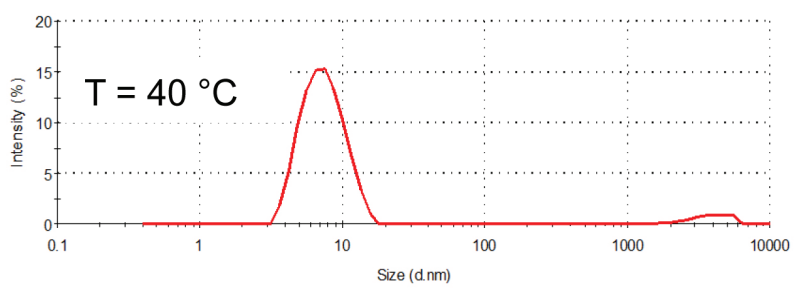

PAAHgB

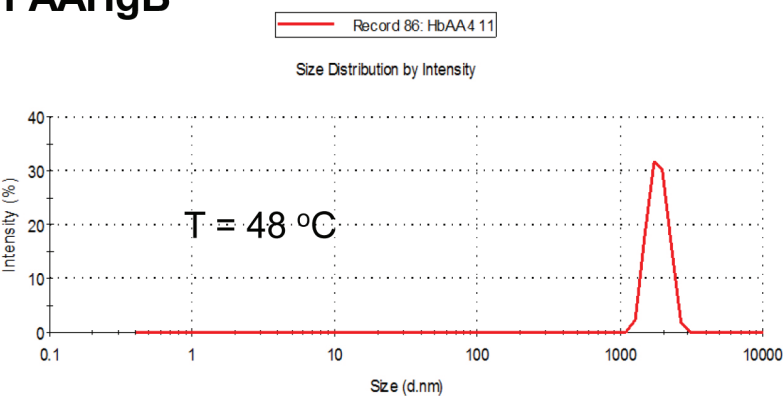

PAAHgB

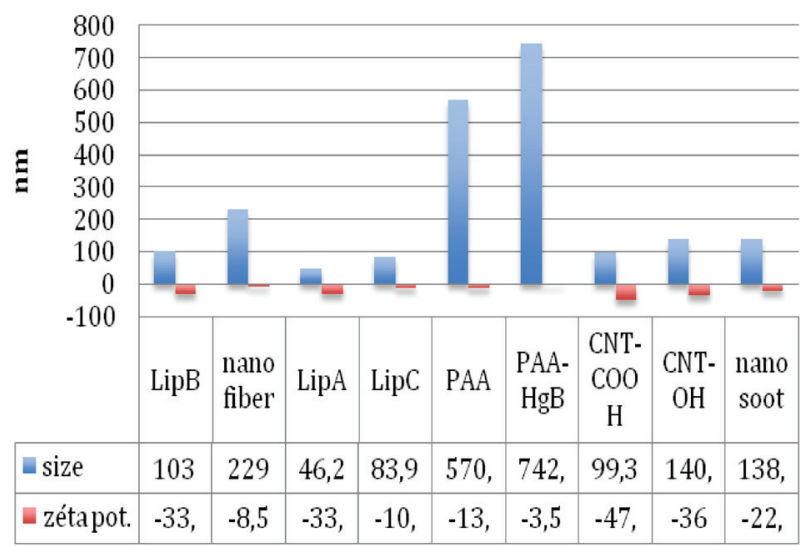

Fig. 4. Comparison of the size and zeta potential of different nanomaterials

(MWCNT) the different surface functionalization fundamentally modifies the level of basophil activation. Strong basophil activation was found in the presence of CNT-OH. The lower rate of CD63 expression was measured in samples containing liposome particles (LipB, LipA, LipC) and nanofibers. Carboxyl functionalized CNT-COOH, PAA and PAAHgB induce also lower rate of CD63 marker. 
$\%$

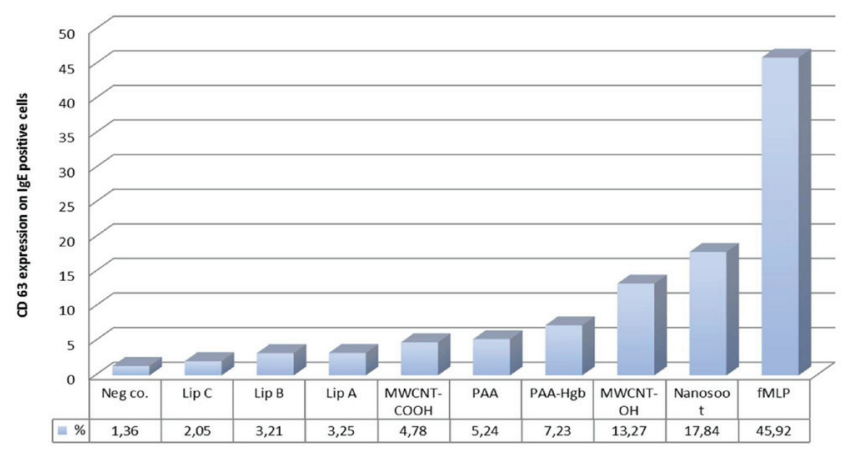

Fig. 5. Basophilic activation test values of different nanomaterials

\section{Conclusions}

Single haemoglobin nanocapsules were synthesized with acrylamide-bisacrylamide copolymer on the surface of the molecules (PAAHgB) and size, homogeneity, aggregation status, zeta potential and allergenic activity (Basophil activation test) was investigated. Natural $\mathrm{HgB}$ molecules and $\mathrm{PAAHgB}$ samples have the same melting point $\left(38^{\circ} \mathrm{C}\right)$. The mean size of PAAHgB (the peak of the size distribution) is less, than $10 \mathrm{~nm}$ while the mean size of empty acrylamide-bisacrylamide copolymer particles (AA) higher than $100 \mathrm{~nm}$. Under $40^{\circ} \mathrm{C}$ the PAAHgB aggregates and at $48^{\circ} \mathrm{C}$ the aggregation will be complete (the peak of its size distribution is higher than $1000 \mathrm{~nm}$ ). The results show that the basophil activation values of PAAHgB nanoparticles in the case of basophil activation kit are in the normal area (0-20\%), however they cause slight direct activation and degranulation on basophil cells when compared with negative control. PAAHgB should be enveloped into liposome in order to reduce its aggregation.

\section{Abbreviations}

SEN :single enzyme nanoparticles

SPN :single protein nanocapsule

PAAHgB :single haemoglobin nanocapsules

TEMED :N,N,N',N'tetramethylethylenediamine

MWCNT :multi wall carbon nanotubes

PAA :polyacrylamide gel

DSL :dynamic light scattering

FACS :Fluorescence-activated cell sorting, a biophysical technique used in flow cytometry

CD63 :antigen marker for flow cytometric quantification of in vitro activated basophils for diagnosis of IgE-mediated allergy

CNT :carbon nanotube

LipA :liposome with $0.07 \mathrm{~g} / \mathrm{mol}$ total phospholipid content

LipB : :liposome with $0.036 \mathrm{~g} / \mathrm{mol}$ phospholipid content

LipC : :liposome with $15,96 \mathrm{~g} / \mathrm{mol}$ phospholipid content

fMLP :formyl-methionyl-leucyl -phenylalanine

\section{Acknowledgements}

This work was supported by the National Development Agency grant (TÁMOP - 4.2.2/B-10/1-2010-0025 and TÁMOP-4.2.1.B-10/2/KONV-2010-0001 project). We thank to Professor János Szebeni (University of Miskolc) for the synthesis of liposomes and for the coordination of the works.

\section{References}

1 Cheetham P.S.J., Principles of industrial biocatalysis and bioprocessing. in 'Handbook of enzyme biotechnology' (ed. Wiseman A.,) Ellis Horwood Ltd., Chichester, UK, 83-234 (1995).

2 Tischer W., Kasche V., Immobilized enzymes: crystals or carriers? Trends in Biotechnology, 17(8), 326-335 (1999). DOI: $10.1016 / \mathrm{S} 0167-7799(99) 01322-0$

3 Livage J., Coradin T., Roux C., Encapsulation of biomolecules in silica gels. Journal of Physics: Condensed Matter, 13(33), R673-691 (2001). DOI: $10.1088 / 0953-8984 / 13 / 33 / 202$

4 Mozhaev V. V., Melik-Nubarov N. S., Sergeeva M. V., Siksnis V., Martinek K., Strategy for stabilizing enzymes, Part One: increasing stability of enzymes via their multi-point interaction with a support. Biocatalysis and Biotransformation, 3(3), 179-187 (1990). DOI: $10.3109 / 10242429008992060$
5 Mozhaev V. V., Mechanism-based strategies for protein thermostabilization. Trends in Biotechnology, 11(3), 88-95 (1993). DOI: 10.1016/0167-7799(93)90057-G

6 Desantis G., Jones J. B., Chemical modification of enzymes for enhanced functionality. Current Opinion in Biotechnology, 10(4), 324-330 (1999). DOI: $\underline{10.1016 / \mathrm{S} 0958-1669(99) 80059-7}$

7 O'fagain C., Enzyme stabilization - recent experimental progress. Enzyme and Microbial Technology, 33(2-3), 137-149 (2003). DOI: $\underline{10.1016 / \mathrm{S} 0141-0229(03) 00160-1}$

8 Jia H., Zhu G., Wang P., Catalytic behaviors of enzymes attached to nanoparticles: the effect of particle mobility. Biotechnology and Bioengineering, 84(4), 406-414 (2003). DOI: $10.1002 /$ bit.10781 
9 Ge J., Lu D., Liu Z., Liu Z., Recent advances in nanostructured biocatalysts. Biochemical Engineering Journal, 44(1), 53-59 (2009). DOI: $10.1016 /$ j.bej.2009.01.002

10 Kim J., Grate J. W., Wang P., Nanostructures for enzyme stabilization. Chemical Engineering Science, 61(3), 1017-1026 (2006). DOI: $10.1016 /$ j.ces.2005.05.067

11 Yan M., Ge Y., Liu Z., Ouyang P. K., Encapsulation of single enzyme in nanogel with enhanced biocatalytic activity and stability. Journal of The American Chemical Society, 128(34), 11008-11009 (2006). DOI: $10.1021 / \mathrm{ja} 064126 \mathrm{t}$

12 Hegedüs I., Nagy E., Improvement of enzyme stability as single enzyme nanoparticles. Chemical Engineering Science, 64(5), 1053-1060 (2009).

DOI: $10.1016 /$ j.ces.2008.10.063

13 Hegedüs I., Nagy E., Comparison of the structure and the stability of single enzyme nanoparticles. Hungarian Journal of Industrial Chemistry, 37(2), 123-130 (2009).

14 Hegedüs I., Hancsók J., Nagy E., Stabilization of the Cellulase Enzyme Complex as Enzyme Nanoparticle. Applied Biochemistry and Biotechnology, 168(6), 1372-1383 (2012).

DOI: $10.1007 / \mathrm{s} 12010-012-9863-9$

15 Hegedus I., Farago E., Nagy E., Kalman M., An attempt to transfer protein molecules through the blood brain barrier. in 'Neuroscience 2011 Society for Neuroscience Annual Meeting' Washington, DC, USA (2011).

16 Kumar R., Maitra A. N., Patanjali P. K., Sharma P., Hollow gold nanoparticles encapsulating horseradish peroxidase. Biomaterials, 26(33), 6743-6753 (2005).

DOI: 10.1016/j.biomaterials.2005.04.045

17 Yang Z., Shihui S., Chunjing Z., Magnetic single-enzyme nanoparticles with high activity and stability. Biochemical and Biophysical Research Communications, 367(1), 169-175 (2008).

DOI: $10.1016 / \mathrm{j}$. bbrc.2007.12.113

18 Ge Y., Minf Y., Lu D., Zhang M., Liu Z., Hyperbranched polymer conjugated lipase with enhanced activity and stability. Biochemical Engineering Journal, 36(2), 93-99 (2007).

DOI: $10.1016 /$ j.bej.2007.02.018
19 Hong J., Xu D., Gong P., Ma H., Dong L., Yao S., Conjugation of Enzyme on superparamagnetic nanogels covered with carboxyl groups. Journal of Chromatography B, 850(1-2), 499-506 (2007). DOI: $10.1016 /$ j.jchromb.2006.12.035

20 Yang Z., Shihui S., Chunjing Z., Magnetic single-enzyme nanoparticles with high activity and stability. Biochemical and Biophysical Research Communications, 367(1), 169-175 (2008). DOI: 10.1016/j.bbrc.2007.12.113

21 Yan M., Du J., Gu Z., Liang M., Hu Y., Zhang W., Priceman S., Wu L., Zhou H., Liu Z., Segura T., Tang Y., Lu Y., A novel intracellular protein delivery platform based on single-protein nanocapsules. Nature Nanotechnology, 5, 48-53 (2010). DOI: $\underline{10.1038 / \text { nnano.2009.341 }}$

22 Du J., Jin J., Yan M., Lu Y., Synthetic Nanocarriers for Intracellular Protein Delivery. Current Drug Metabolism, 13(1), $82-92$ (2012). DOI: $\underline{10.2174 / 138920012798356862}$

23 Gill I., Ballesteros A., Bioencapsulation within synthetic polymers (Part 1): sol-gel encapsulated biologicals. Trends in Biotechnology, 18(7), 282-296 (2000). DOI: $10.1016 / \mathrm{S} 0167-7799(00) 01457-8$

24 Lee K. Y., Yuk S. H., Polymeric protein delivery systems. Progress in Polymer Science, 32(7), 669-697 (2007). DOI: 10.1016/j.progpolymsci.2007.04.001

25 Sharma A., Arora S., Grewal P., Dhillon V., Kumar V., Recent innovations in delivery of artificial blood substitute: a review. International Journal of Applied Pharmaceutics, 3(2), 1-5 (2011).

26 Szebeni J., Muggia F., Gabizon A., Barenholz Y., Activation of complement by therapeutic liposomes and other lipid excipient-based therapeutic products: Prediction and prevention. Advanced Drug Delivery Reviews, 63(12), 1020-1030 (2011). DOI: $\underline{10.1016 / \text { j.addr.2011.06.017 }}$ 